\title{
Acesso à Justiça e Igualdade: críticas à Resolução No 174/2016 do Conselho Superior da Justiça do Trabalho
}

\author{
Acces to Justice and Equality: review about Resolution $\mathbf{N}^{\circ}$ \\ 174/2016 of the Superior Council of Labor Justice
}

Daniel Mota Gutiérrez ${ }^{1}$

Victor Alves Magalhães ${ }^{2}$

\begin{abstract}
RESUMO:
O objetivo deste trabalho esteve em confrontar as determinações proferidas pelo Conselho Superior da Justiça do Trabalho em sua Resolução ${ }^{\circ} 174$ com os princípios constitucionais de igualdade e de acesso à justiça, utilizando-se de dados oficiais do Justiça em Números, promovido pelo Conselho Nacional de Justiça, com um corte metodológico estabelecido para comparar a incongruência do que foi determinado pelos magistrados e os números que refletiam a realidade daquele ano, chegando-se ao ponto de concluir que a referida Resolução evita que o caminho de descentralização da função jurisdicional dos juízes togados em direção aos cidadãos se concretize, promovendo assim que tanto seja inviável uma real distribuição do Poder decisório, bem como, que o processo possa se tornar algo mais democrático, exatamente pelo fato de não se observar o acesso à justiça ou a igualdade em tal regulação.
\end{abstract}

\section{PALAVRAS-CHAVE:}

Igualdade. Acesso à Justiça. Legitimidade. Resolução. Leis Trabalhistas.

\begin{abstract}
:
The aim of this work was to confront the determinations made by the Board of Governors of the labour courts in your Resolution $\mathrm{n}^{\circ} 174$ with the constitutional principles of equality and access to justice, using official data from Justice in numbers, sponsored by the National Council of Justice, with a methodological court established to compare the incongruity of what was determined by the judges and the numbers reflected the reality that year, coming to the conclusion that the resolution prevents the path of decentralization of the judicial function of the judges towards the citizens to materialize, thereby promoting that both is impossible a real decision-making power distribution, as well as, the process can become something more democratic, exactly because they don't observe the access to justice or equality in such regulation.
\end{abstract}

KEYWORDS:

Equality. Access to justice. Legitimacy. Resolution. Labor Law.

\footnotetext{
${ }^{1}$ Professor da Graduação e Pós-Graduação do Centro Universitário Christus - Fortaleza, Ceará, Brasil. Doutor em Direito pela Pontifícia Universidade Católica de São Paulo. Mestre em Direito pela Pontifícia Universidade Católica de São Paulo. E-mail: dgutierrez@uol.com.br.

${ }^{2}$ Mestrando em Direito pelaUniversidade Federal do Ceará (Fortaleza - Brasil). Pós-Graduando em Gestão Educacional pela Faculdade Damásio-SP. Graduado em Direito pela Universidade Federal do Ceará. Pesquisador e advogado. E-mail: victoralvesmagal@gmail.com.
} 


\section{CONSIDERAÇÕES INICIAIS}

O Judiciário brasileiro aparenta atravessar uma espécie de "crise estrutural", instituída com a redemocratização do país, quando a Constituinte lhe atribuiu papel central na concretização das garantias promovidas pelo Estado, com um protagonismo consagrado pelo princípio da inafastabilidade da tutela jurisdicional (versado pelo inciso XXXV do artigo $5^{\circ}$ da CRFB de 1988).

Tal percepção é verificada quando o Conselho Nacional de Justiça (CNJ) começou suas análises com os dados fornecidos pelos anualmente publicados "Justiça em Números" ${ }^{3}$, que fornecem as principais estatísticas do referido Poder, demonstrando o descompasso existente entre a demanda apresentada ao Judiciário pela sociedade e os recursos (financeiros e humanos) que os Tribunais possuem para cumprir com seu papel constitucional.

Notório foi o visível intuito do legislador originário em proteger as garantias e direitos (tolhidos pelas duas décadas de uma ditadura ainda muito recente na história nacional), contudo, começou-se a perceber que o foco excessivo no Poder Judicante, com o passar dos anos, enfraqueceu outros meios capazes de proteger e efetivar o devido retorno, para a sociedade, do que foi primordialmente estabelecido pela Constituição ${ }^{4}$.

A institucionalização que o Judiciário - por meio de seus principais atores (magistrados) - seria competente para resolver todos os problemas de uma população ${ }^{5}$ que ultrapassa duzentos milhões de habitantes, somado com as benesses da Justiça Gratuita, acabou causando uma grande dependência da população brasileira em seus juízes, os quais finalizaram o ano de 2017 com 80,1 milhões de processos em tramitação ${ }^{6}$.

\footnotetext{
${ }^{3}$ Todos os relatórios, desde o ano de 2004, podem ser encontrados no sítio do CNJ, disponível em: http://www.cnj.jus.br/programas-e-acoes/pj-justica-em-numeros. Acesso em: 9 de mai. 2018.

${ }^{4}$ CAPPELLETTI, Mauro; GARTH Bryant. Acesso à justiça. Porto Alegre, Sérgio Antonio Fabris, 1988, p. 164165.

${ }^{5}$ Sobre o assunto, as críticas de Ingeborg Maus (traduzidas por Martonio M. B. Lima e Paulo Antonio de M. Albuquerque) no artigo Judiciário como Superego da Sociedade - O Papel da Atividade Jurisprudencial na "Sociedade Órfã" são pertinentes. Disponível em: <http://www.direitocontemporaneo.com/wpcontent/uploads/2014/02/JUDICI\%C3\%81RIO-COMO-SUPEREGO-DA-SOCIEDADE.pdf>. Acesso em: 9 de mai. 2018

${ }^{6}$ BRASIL. Justiça em Números 2018: ano-base 2017. Conselho Nacional de Justiça - Brasília: CNJ, 2018, p.73 
Assim, em face do alto número de demandas apresentadas perante o Judiciário, passando a comprometer, dessa forma, a própria efetividade dos direitos e garantias que deveriam ser proporcionados por esse, fez-se necessária uma revisão do papel atribuído pelos constituintes originários aos juízes - iniciada em 2004 com a Emenda Constitucional n ${ }^{\circ} 45$-que concedeu ao "acesso à justiça" e a "celeridade processual" o status de garantias fundamentais do ordenamento jurídico brasileiro.

Com tais garantias estabelecidas, uma das medidas foi a criação do Conselho Nacional de Justiça, que tem por algumas de suas metas: planejar políticas públicas, modernizar o Poder Judiciário e ampliar o acesso à justiça.

Entre as diversas medidas adotadas pelo Conselho Nacional de Justiça, visando implementar tais objetivos e proporcionar uma maior autonomia e igualdade para os eventuais envolvidos em litígios, surgiu a Resolução n 125 de 2010 (atualmente com duas emendas, sendo a última do ano de 2016, para adaptar ao contexto do novo Código de Processo Civil e a Lei de Mediação, ambos de 2015), que dispõe sobre a "Política Judiciária Nacional de tratamento adequado dos conflitos de interesses no âmbito do Poder Judiciário".

O tratamento dessa resolução promovida pelo CNJ (cuja presidência é ocupada pelo ministro presidente do Supremo Tribunal Federal em exercício), considera, entre outros fatores, "que o direito de acesso à Justiça, previsto no art. $5^{\circ}, \mathrm{XXXV}$, da Constituição Federal além da vertente formal perante os órgãos judiciários, implica acesso à ordem jurídica justa"7.

Apesar do conceito inicial abstrato de "ordem jurídica justa" adotado pelo órgão, ainda nas considerações iniciais da Resolução do CNJ, existe uma "consequência" decorrente do direito de acesso à Justiça, que seria estabelecer uma política pública de tratamento adequado dos problemas jurídicos e dos conflitos de interesses, organizada em âmbito nacional. Tal aspecto não envolveria somente os serviços prestados nos processos judiciais, mas também aqueles que possam sê-lo mediante outros mecanismos de solução de conflitos, em especial os

7 CONSELHO NACIONAL DE JUSTIÇA. Resolução no 125 , de 29 de novembro de 2010. Dispõe Sobre A Política Judiciária Nacional de Tratamento Adequado dos Conflitos de Interesses no âmbito do Poder Judiciário e Dá Outras Providências. Diário Oficial da União: Brasília, DF, $1^{\circ}$ dez. 2010. Disponível em: http://cnj.jus.br/images/atos_normativos/resolucao/resolucao_125_29112010_11032016150808.pdf. Acesso em: 9 mai. 2018, p. 1 
consensuais, como a mediação e a conciliação, seja dentro ou fora do Judiciário. Com isso, facilita-se a interpretação do que seria "justo", na busca do acesso à Justiça, para o Conselho Nacional de Justiça ${ }^{8}$.

Prosseguindo nos objetivos que levaram a existência desta Resolução $\mathrm{n}^{\circ} 125$, existe ainda a necessidade de organização e uniformização dos serviços de conciliação, mediação e outros métodos consensuais de solução de conflitos, para evitar disparidades de orientações e práticas, visando assegurar a boa execução dessa política ${ }^{9}$.

Como reforço sobre esses ideais estabelecidos pelo CNJ, o legislador estabeleceu no primeiro parágrafo do artigo 165 do Código de Processo Civil de $2015^{10}$ que, apesar da composição e organização dos centros judiciários de solução consensual de conflitos (órgãos que possuem como objetivo primordial auxiliar a concretização da política pública que o CNJ já abordara em sua Resolução $n^{\circ} 125$ ) ser dos Tribunais, as normas do CNJ precisariam ser observadas.

Entretanto, apesar de todo esse contexto e conforme irá ser pontuado adiante, o Conselho Superior da Justiça do Trabalho (CSJT), atuando de maneira contrária ao disposto tanto pelo CNJ quanto pela legislação pátria, apresentou sua própria Resolução ( $\left.\mathrm{n}^{\circ} 174\right)$ em setembro de 2016 que, em diversos pontos, versou de maneira contrária ao espírito da política nacional que vinha sendo construído pelo CNJ, incongruência que motivou este ensaio.

Escolheu-se para análise desse trabalho os dados provenientes do relatório Justiça em Números, que possuiu como ano-base 2016 (mesmo da publicação da Resolução do CSJT em debate), com o objetivo de demonstrar o descompasso entre a realidade dos números

\footnotetext{
${ }^{8}$ CONSELHO NACIONAL DE JUSTIÇA. Resolução no 125, de 29 de novembro de 2010. Dispõe Sobre A Política Judiciária Nacional de Tratamento Adequado dos Conflitos de Interesses no âmbito do Poder Judiciário e Dá Outras Providências. Diário Oficial da União: Brasília, DF, $1^{\circ}$ dez. 2010. Disponível em: http://cnj.jus.br/images/atos_normativos/resolucao/resolucao_125_29112010_11032016150808.pdf. Acesso em: 9 mai. 2018, p.1

${ }^{9}$ CONSELHO NACIONAL DE JUSTIÇA. Resolução no 125, de 29 de novembro de 2010. Dispõe Sobre A Política Judiciária Nacional de Tratamento Adequado dos Conflitos de Interesses no âmbito do Poder Judiciário e Dá Outras Providências. Diário Oficial da União: Brasília, DF, $1^{\circ}$ dez. 2010. Disponível em: http://cnj.jus.br/images/atos_normativos/resolucao/resolucao_125_29112010_11032016150808.pdf. Acesso em: 9 mai. 2018, p.1-2

${ }^{10}$ BRASIL. Lei 13.105, de 16 de março de 2015. Código de Processo Civil. Diário Oficial da União: Brasília, DF, 17 mar. 2015. Disponível em: http://www.planalto.gov.br/ccivil_03/_ato2015-2018/2015/lei/l13105.htm. Acesso em 14 mai. 2018
} 
apresentados pelo $\mathrm{CNJ}$ e as decisões dos magistrados do principal órgão deliberativo da Justiça do Trabalho no Brasil naquele ano.

Com o intuito de reforçar tais críticas, será utilizado o relatório Justiça em Números que teve como ano-base 2017, publicado no final de 2018 pelo CNJ, para comparar os índices de conciliação na Justiça do Trabalho e saber se a vigência da Resolução de 2016 afetou tais estatísticas de alguma maneira.

Ao dispor sobre a política judiciária nacional de tratamento adequado das disputas de interesses no âmbito do Poder Judiciário Trabalhista, a resolução n ${ }^{\circ} 174$ do CSJT em diversos pontos não apenas deixou de seguir o que estava sendo estabelecido para todo o Judiciário brasileiro, mas em seu cerne, desestabilizou o acesso à Justiça que visava trazer uma maior autonomia para os jurisdicionados resolverem seus conflitos e a própria igualdade de posições inerente desse contexto, afetando com isso até mesmo a seleção dos futuros mediadores e conciliadores desse ramo do Judiciário.

Em outro trabalho ${ }^{11}$, buscou-se analisar a mesma situação da Resolução ${ }^{\circ} 174$ do CSJT por uma visão de gestão e incongruência com o orçamento público. Agora, com fundamento neste primeiro olhar, foi avaliado como a compreensão dos magistrados trabalhistas sobre a referida Resolução esbarra em fundamentos constitucionais como o acesso à justiça e a própria igualdade.

\section{QUANDO O ACESSO À JUSTIÇA É NEGADO PELO PRÓPRIO JUDICIÁRIO}

Comparando-se ambas as Resoluções que até o momento vinham sendo tratadas ( $\mathrm{n}^{\circ} 125$ do CNJ e $\mathrm{n}^{\circ} 174$ do CSJT), são percebidos diversos pontos de incongruência entre o posicionamento proveniente do órgão responsável pelo controle da atuação administrativa do

\footnotetext{
${ }^{11}$ MAGALHÃES, Victor Alves e MELO, Marcelo Sampaio de Couto. Prejuízos de uma política pública sem gestão e estatísticas: o caso da Resolução N ${ }^{\circ}$ 174/2016 do Conselho Superior da Justiça do Trabalho. Revista Inclusiones, v. 5. n. 4, p. 95-107, out./dez. 2018. Disponível em: http://www.revistainclusiones.com/gallery/6\%20vol\%205\%20num\%204\%202018cruzvadillooctubrediciembrerv \%20inclu.pdf. Acesso em: 12 nov. 2018.
} 
Poder Judiciário $^{\mathbf{1 2}}$ (CNJ) e o órgão criado pela mesma Emenda Constitucional (nº 45 de 2004) para a supervisão administrativa, orçamentária, financeira e patrimonial da Justiça do Trabalho $^{\mathbf{1 3}}$ (CSJT).

Relembrando aqui que o direito fundamental de acesso à justiça, pela visão do CNJ, busca estabelecer uma política pública de tratamento adequado não somente para os serviços prestados nos processos judiciais, como também para outros mecanismos de soluções consensuais de conflitos. Apontados serão, assim, alguns aspectos ao longo deste trabalho que demonstram uma conduta oposta e contraditória ao referido direito, por parte do CSJT.

\subsection{Formação dos servidores para exercerem atividades que não eram o propósito da sua seleção}

A primeira inconsistência determinada pela Resolução $n^{\circ} 174$ do CSJT, observada em seu inciso II do artigo $3^{\circ}$, seria esta: "a adequada formação e treinamento de servidores e magistrados para exercer a conciliação e mediação, podendo - para este fim - ser firmadas parcerias com entidades públicas e privadas"14.

Quando os ministros que coordenam o CSJT instituem que, para implementar esse projeto de "tratamento de disputas", é fundamental a formação e treinamento de servidores e magistrados para exercer a conciliação e mediação, mostra-se evidente o completo

\footnotetext{
${ }^{12}$ BRASIL. Constituição (1988). Constituição da República Federativa do Brasil: promulgada em 5 de outubro de 1988, atualizada até a Emenda Constitucional $\mathrm{n}^{\circ}$ 99, de 14 de dezembro de 2017. Disponível em: http://www.planalto.gov.br/ccivil_03/constituicao/constituicaocompilado.htm. Acesso em 10 mai. 2018. Parágrafo quarto do art. 103-B.

${ }^{13}$ BRASIL. Constituição (1988). Constituição da República Federativa do Brasil: promulgada em 5 de outubro de 1988, atualizada até a Emenda Constitucional $\mathrm{n}^{\circ}$ 99, de 14 de dezembro de 2017. Disponível em: http://www.planalto.gov.br/ccivil_03/constituicao/constituicaocompilado.htm. Acesso em 10 mai. 2018. Inciso II do parágrafo segundo do art. 111-A.

${ }^{14}$ CONSELHO SUPERIOR DA JUSTIÇA DO TRABALHO. Resolução $\mathrm{n}^{\circ}$ 174, de 30 de setembro de 2016. Dispõe Sobre A Política Judiciária Nacional de Tratamento Adequado das Disputas de Interesses no âmbito do Poder Judiciário Trabalhista e Dá Outras Providências. Diário Eletrônico da Justiça do Trabalho: Brasília, DF, n. 2079, 5 out. 2016. Caderno Administrativo do Conselho Superior da Justiça do Trabalho. Disponível em: http://www.csjt.jus.br/c/document_library/get_file?uuid=235e3400-9476-47a0-8bbb-

bccacf94fab4\&groupId=955023. Acesso em: 10 mai. 2018. p. 1-6.
} 
desconhecimento da realidade que os dados angariados pelo CNJ anualmente demonstram sobre os Tribunais da Justiça do Trabalho.

Em um cenário que o índice de produtividade e da carga de trabalho dos magistrados e servidores da Justiça do Trabalho é completamente desproporcional (e apenas aumenta ao longo dos anos), demonstrando uma carência significativa neste ramo, é evidente que atribuir para esses profissionais mais uma função (que demandará grande carga horária para especialização e posterior implementação), não parece uma escolha que reflete a realidade da situação do Poder Judiciário em seu ramo Trabalhista, principalmente para promover o acesso à justiça com um serviço especializado aos cidadãos, conforme os gráficos 1 e 2 demonstram.

Gráfico 1 - Séries históricas do índice de produtividade e da carga de trabalho dos magistrados, por ramo de Justiça.

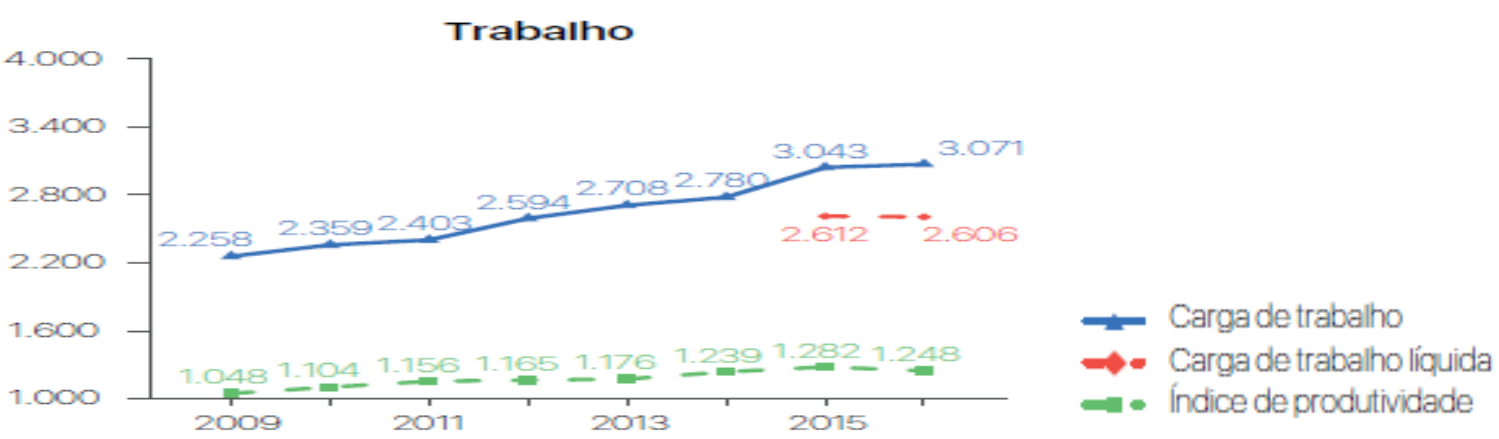

Fonte: BRASIL. Justiça em Números 2017: ano-base 2016. Conselho Nacional de Justiça Brasília: CNJ, 2017. p. 71.

Gráfico 2 - Séries históricas do índice de produtividade e da carga de trabalho dos servidores da área judiciária, por ramo de Justiça

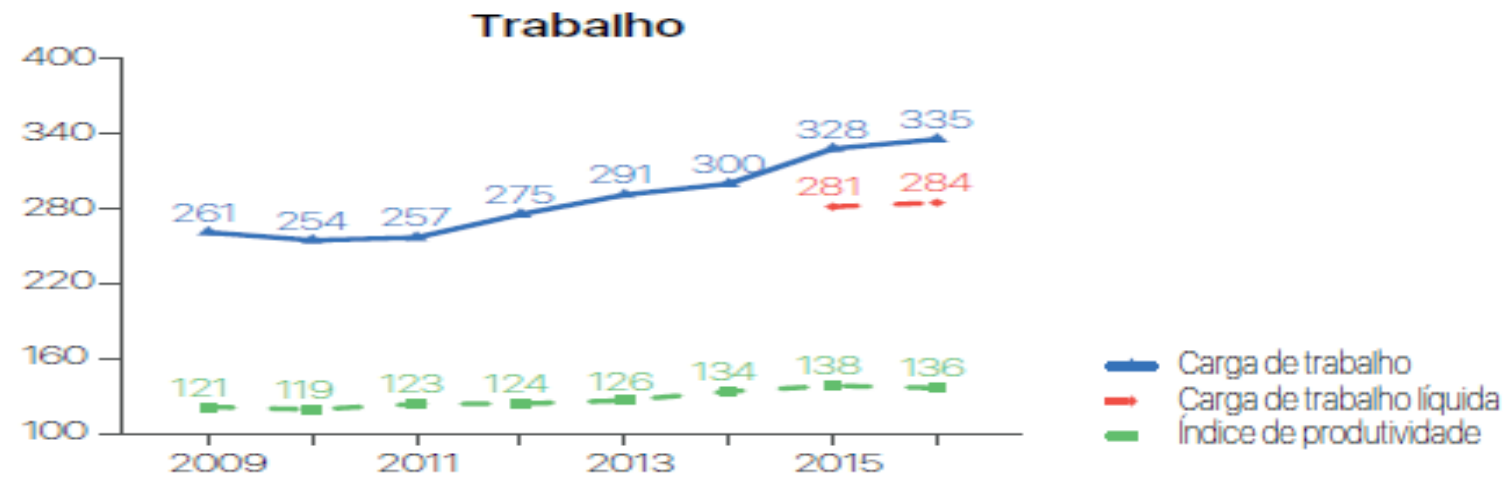

Fonte: BRASIL. Justiça em Números 2017: ano-base 2016. Conselho Nacional de Justiça Brasília: CNJ, 2017. p. 74. 
Ou seja: ao invés de atribuir ainda mais tarefas aos servidores e magistrados já sobrecarregados da Justiça do Trabalho, que não possuem como função principal ou mesmo prestaram concurso para, repentinamente, terem que implementar uma "Política Judiciária Nacional de tratamento das disputas de interesses trabalhistas", bem mais eficaz seria - para a dinâmica do trabalho das cortes - contratar conciliadores e mediadores que poderiam se focar nas atividades para os quais foram designados e treinados antecipadamente para exercer, até mesmo em face da interdisciplinaridade necessária para o exercício desta função ${ }^{15}$ e que não apenas os conhecimentos jurídicos conseguem suprir.

Poderia ser solucionado de maneira mais efetiva, assim, a demanda específica das soluções consensuais, promovendo-se uma maior viabilidade da política pública almejada pelo CNJ.

\subsection{Centralização desnecessária e contraproducente}

Tal ideia esbarra em outro problema, contudo, contido na Resolução n ${ }^{\circ} 174$ do CSJT: a centralização. Entre outras formas, é explícita no inciso I do artigo $3^{\circ}$ : "a centralização das estruturas judiciárias de solução consensual de disputas" ${ }^{16}$. Quando os ministros que compõem o referido órgão decidiram adotar esse posicionamento, aparentemente esqueceram do acesso à justiça e da igualdade de tratamento que devem ser fornecidos para os que recorrem ao Judiciário.

O próprio constituinte derivado, afinal, na emenda constitucional $n^{\circ} 45$, estabeleceu que os Tribunais Regionais do Trabalho instalariam uma justiça itinerante, com a realização de audiências e demais funções da atividade jurisdicional, nos limites territoriais da respectiva

\footnotetext{
${ }^{15}$ FILPO, Klever Paulo Leal. Conflitos não-mediáveis ou conflitos latentes? Aportes interdisciplinares para pensar a mediação em juízo na Lei13.105/2015. Revista Juris Poiesis ano 19, n ${ }^{\circ}$ 19, jan-mai.2016. Disponível em: http://revistaadmmade.estacio.br/index.php/jurispoiesis/article/viewFile/2024/1035. Acesso em: 31 jan. 2019, p. 28-30

${ }^{16}$ CONSELHO SUPERIOR DA JUSTIÇA DO TRABALHO. Resolução $\mathrm{n}^{\circ}$ 174, de 30 de setembro de 2016. Dispõe Sobre A Política Judiciária Nacional de Tratamento Adequado das Disputas de Interesses no âmbito do Poder Judiciário Trabalhista e Dá Outras Providências. Diário Eletrônico da Justiça do Trabalho: Brasília, DF, n. 2079, 5 out. 2016. Caderno Administrativo do Conselho Superior da Justiça do Trabalho. Disponível em: http://www.csjt.jus.br/c/document_library/get_file?uuid=235e3400-9476-47a0-8bbb-

bccacf94fab4\&groupId=955023. Acesso em: 10 mai. 2018. p. 1-6.
} 
jurisdição e que poderiam funcionar descentralizadamente, constituindo Câmaras Regionais, a fim de assegurar o pleno acesso do jurisdicionado à Justiça em todas as fases do processo ${ }^{17}$.

Em sentido contrário, o que se vê é o engessamento regulatório - promovido pelo principal órgão da Justiça do Trabalho brasileira - dos métodos consensuais, não permitindo o desenvolvimento orgânico desses. Em uma ânsia pelo controle da evolução de tais meios em sua seara, os ministros que compõem o CSJT acabaram por sequer considerar o que está estabelecido na Constituição Federal (desde o ano de 2004), para um efetivo funcionamento da própria Justiça do Trabalho, que é exatamente: torná-la descentralizada.

Ilustrando a centralização abusiva por parte do CSJT, podem ser analisados os parágrafos primeiro e oitavo do artigo $6^{\circ}$ da Resolução $n^{\circ} 174 / 2016$, iniciando-se pelo fato das sessões de conciliação e mediação realizadas nos Centros Judiciários de Métodos Consensuais de Solução de Disputas da Justiça do Trabalho (CEJUSC-JT) terem que contar com a presença física de magistrado, o qual poderá atuar como conciliador e mediador e supervisionará a atividade dos conciliadores e mediadores, estando sempre disponível às partes e advogados ${ }^{18}$.

Apesar de ser inegável que a presença dos magistrados serviria para o bom funcionamento de um CEJUSC-JT, é completamente desproporcional a exigência da presença física desses em todas as sessões de mediação e conciliação que viriam a ocorrer nesses espaços. Afinal, para que então o CNJ estabeleceria todo um cronograma de formação teórica e prática para os profissionais que fossem conduzir tais atos ${ }^{19}$ ?

\footnotetext{
${ }^{17}$ BRASIL. Constituição (1988). Constituição da República Federativa do Brasil: promulgada em 5 de outubro de 1988, atualizada até a Emenda Constitucional $\mathrm{n}^{\circ}$ 99, de 14 de dezembro de 2017. Disponível em: http://www.planalto.gov.br/ccivil_03/constituicao/constituicaocompilado.htm. Acesso em 10 mai. 2018. Parágrafos $1^{\circ}$ e $2^{\circ}$ do art. 115.

${ }^{18}$ CONSELHO SUPERIOR DA JUSTIÇA DO TRABALHO. Resolução no 174, de 30 de setembro de 2016. Dispõe Sobre A Política Judiciária Nacional de Tratamento Adequado das Disputas de Interesses no âmbito do Poder Judiciário Trabalhista e Dá Outras Providências. Diário Eletrônico da Justiça do Trabalho: Brasília, DF, n. 2079, 5 out. 2016. Caderno Administrativo do Conselho Superior da Justiça do Trabalho. Disponível em: http://www.csjt.jus.br/c/document_library/get_file?uuid=235e3400-9476-47a0-8bbbbccacf 94 fab4\&groupId=955023. Acesso em: 10 mai. 2018. Parágrafo primeiro do art. $6^{\circ}$.

${ }_{19}$ Diretrizes Curriculares para terceiros facilitadores (conciliadores e mediadores) foram estabelecidas pela emenda $\mathrm{n}^{\circ} 02 \mathrm{em} 8$ de março de 2016, meses antes da Resolução do CSJT em análise. (CONSELHO NACIONAL DE JUSTIÇA. Resolução no 125, de 29 de novembro de 2010. Dispõe Sobre A Política Judiciária Nacional de Tratamento Adequado dos Conflitos de Interesses no âmbito do Poder Judiciário e Dá Outras Providências. Diário Oficial da União: Brasília, DF, $1^{\circ}$ dez. 2010. Disponível em: http://cnj.jus.br/images/atos_normativos/resolucao/resolucao_125_29112010_11032016150808.pdf. Acesso em: 9 mai. 2018).
} 
O principal problema dessa determinação é evidente para os magistrados: ao invés de estarem julgando o que, de fato, já foi judicializado, estarão simplesmente supervisionando sessões de algo que ainda é extrajudicial ou que ainda está em um primeiro momento da lide, onde a única real necessidade de um juiz seria a de estabelecer a homologação do acordo posteriormente, no caso de sucesso da sessão.

Ora, se um dos objetivos do Estado em investir nesses métodos é, exatamente, melhorar o fluxo das demandas que permeiam o Judiciário Trabalhista, fica evidente que vincular a presença física de um magistrado - durante sessões que não precisariam dele para ocorrer - é o tipo de decisão completamente contrária aos objetivos de tais técnicas, "norteadas por princípios como informalidade, simplicidade, economia processual, celeridade, oralidade e flexibilidade processual $^{20 "}$.

A incompatibilidade lógica entre as determinações do CSJT e do CNJ são tamanhas, que o segundo já tinha estabelecido que apenas a supervisão do juiz coordenador do centro era suficiente, desde que as sessões de conciliação e mediação judiciais sejam realizadas por conciliadores e mediadores cadastrados pelo tribunal ${ }^{21}$, sendo completamente desnecessária a presença física de magistrados nas sessões.

Continuando com os aspectos prejudiciais da centralização por parte do CSJT, ainda no parágrafo primeiro do sexto artigo da Resolução $\mathrm{n}^{\circ} 174$ desse órgão, apesar da Justiça do Trabalho ser um ramo do Judiciário destinado para relações que envolvam (em regra) trabalhadores hipossuficientes em um dos lados do conflito - aspecto que nunca pode ser olvidado no contexto trabalhista - acredita-se que tornar obrigatória a presença de um advogado para o Reclamante em tais sessões precisaria ser melhor sopesado.

A práxis forense neste ramo, afinal, é conhecida por ser implacável na busca pela judicialização de casos, em busca de honorários advocatícios fáceis. Não por outro motivo que

\footnotetext{
${ }^{20}$ CONSELHO NACIONAL DE JUSTIÇA. Programas e Ações - Conciliação e Mediação. Brasília, [s.d.], sítio eletrônico. Disponível em: http://www.cnj.jus.br/programas-e-acoes/conciliacao-e-mediacao-portal-daconciliacao. Acesso em: 14 mai. 2018.

${ }^{21}$ CONSELHO NACIONAL DE JUSTIÇA. Resolução n ${ }^{\circ}$ 125, de 29 de novembro de 2010. Dispõe Sobre A Política Judiciária Nacional de Tratamento Adequado dos Conflitos de Interesses no âmbito do Poder Judiciário e Dá Outras Providências. Diário Oficial da União: Brasília, DF, $1^{\circ}$ dez. 2010. Disponível em: http://cnj.jus.br/images/atos_normativos/resolucao/resolucao_125_29112010_11032016150808.pdf. Acesso em: 9 mai. 2018, p. 5, parágrafo primeiro, artigo oitavo.
} 
a Ordem dos Advogados do Brasil (OAB) trava uma luta constante contra ilegalidades, como as praticadas por laçadores ${ }^{22}$ e advogados que se utilizam de tais "serviços", característica bastante comum no âmbito da Justiça do Trabalho e que precisa ser melhor fiscalizada para proteger os empregados de abusos cometidos pelos seus próprios patronos. Tal necessidade de patrocínio jurídico (criada pela Resolução da CSJT), para um ato informal no restante do Poder Judiciário, assim, poderia sujeitar os trabalhadores a serem vítimas de uma espécie de abuso, quando essencialmente, sequer precisariam ter este risco, já que um advogado é desnecessário neste ato.

Inclusive, outro fator relacionado com essa vinculação ao advogado seriam os efeitos na igualdade das partes, que deveria ser inerente para os envolvidos no conflito, pois no uso da autonomia de suas vontades, poderiam essas até mesmo definirem quais seriam as regras procedimentais da sua sessão de mediação ou de conciliação ${ }^{23}$. É evidente, assim, que o trabalhador não pode ser caracterizado como hipossuficiente em um ato dessa espécie (pelo menos, não em um nível tão alto como a legislação trabalhista determina em âmbito jurídicoprocessual para os reclamantes), podendo o patrocínio obrigatório acabar afetando a ideia de equidade nesse momento, quando o procedimento deveria ser informal.

Ainda sobre a temática, tal aspecto vai de encontro ao princípio do jus postulandi inerente as demandas laborais e expresso na Consolidação das Leis do Trabalho, onde a parte não precisa do acompanhamento de um advogado em sua reclamação até o final do processo (apesar da existência da súmula $n^{\circ} 425$ do Tribunal Superior do Trabalho ${ }^{24}$, que restringiu tal direito para a primeira e segunda instância), então, qual seria a explicação lógica para que os

\footnotetext{
22"Os "laçadores", como são chamados no meio da advocacia, são atravessadores que ganham comissão pelo agenciamento de causas e 'recrutam' clientes em torno dos Fóruns trabalhistas para que os mesmos entrem com ações contra empresas e patrões. Tais problemas trabalhistas muitas vezes, nem existem, mas os "laçadores" acabam por convencer a pessoa abordada a abrir um processo, pois os escritórios cobram dos clientes para abrir tais ações" (ORDEM DOS ADVOGADOS DO BRASIL - CEARÁ. Diga Não ao Laçador: campanha combate prática ilegal da advocacia. Fortaleza, $1^{\circ}$ out. 2014, sítio eletrônico. Disponível em: http://oabce.org.br/2014/10/diga-nao-ao-lacador-campanha-combate-pratica-ilegal-da-advocacia/. Acesso em: 14 mai. 2018).

${ }^{23}$ BRASIL. Lei 13.105, de 16 de março de 2015. Código de Processo Civil. Diário Oficial da União: Brasília, DF, 17 mar. 2015. Disponível em: http://www.planalto.gov.br/ccivil_03/_ato2015-2018/2015/lei/l13105.htm. Acesso em 14 mai. 2018. Parágrafo quarto do artigo 166.

${ }^{24}$ BRASIL. Tribunal Superior do Trabalho. Súmula n ${ }^{\circ} 425$. O jus postulandi das partes, estabelecido no art. 791 da CLT, limita-se às Varas do Trabalho e aos Tribunais Regionais do Trabalho, não alcançando a ação rescisória, a ação cautelar, o mandado de segurança e os recursos de competência do Tribunal Superior do Trabalho. Diário Eletrônico da Justiça do Trabalho: Brasília, DF, divulgado em 30.04.2010 e 03 e 04.05.2010. Disponível em: http://www3.tst.jus.br/jurisprudencia/Sumulas_com_indice/Sumulas_Ind_401_450.html\#SUM-425. Acesso em: 31 jan. 2019.
} 
reclamantes possam alcançar os Tribunais Regionais do Trabalho sem advogado com sua lide, mas não podem entrar em uma audiência de conciliação desacompanhados?

Em última análise do prejuízo que a centralização causa, vejamos a íntegra do oitavo parágrafo do sexto artigo da Resolução $\mathrm{n}^{\circ} 174$ do CSJT: "Fica vedada a realização de conciliação ou mediação judicial, no âmbito da Justiça do Trabalho, por pessoas que não pertençam aos quadros da ativa ou inativos do respectivo Tribunal Regional do Trabalho"25.

Ao proibir pessoas que não pertençam aos quadros de determinado Tribunal Regional do Trabalho de realizar as sessões de conciliação e mediação, está a Resolução em debate não somente limitando o número de profissionais, mas estabelecendo um regulamento que vai além dos requisitos que o próprio CNJ e as Leis subsequentes (Código de Processo Civil e Lei da Mediação) estabeleceram, acabando com qualquer igualdade que porventura poderia existir nos certames para seleção de facilitadores.

Para a mediação, é preciso ser graduado há pelo menos dois anos em qualquer área de formação ${ }^{26}$, bem como, ser capacitado, por meio de curso realizado por entidade credenciada, conforme parâmetro curricular definido pelo CNJ em conjunto com o Ministério da Justiça, nos moldes da grade curricular contida na Resolução $\mathrm{n}^{\circ} 125$ do referido Conselho.

É possível, além disso, legalmente atuar como mediador ou conciliador em vários tribunais, podendo o tribunal optar pela criação de quadro próprio, que deveria ser preenchido por concurso público de provas e títulos ${ }^{27}$. Não existe nada em lei que autorize tamanha

\footnotetext{
${ }^{25}$ CONSELHO SUPERIOR DA JUSTIÇA DO TRABALHO. Resolução no 174, de 30 de setembro de 2016. Dispõe Sobre A Política Judiciária Nacional de Tratamento Adequado das Disputas de Interesses no âmbito do Poder Judiciário Trabalhista e Dá Outras Providências. Diário Eletrônico da Justiça do Trabalho: Brasília, DF, n. 2079, 5 out. 2016. Caderno Administrativo do Conselho Superior da Justiça do Trabalho. Disponível em: http://www.csjt.jus.br/c/document_library/get_file?uuid=235e3400-9476-47a0-8bbbbccacf94fab4\&groupId=955023. Acesso em: 10 mai. 2018. Parágrafo oitavo do art. $6^{\circ}$.

${ }^{26}$ BRASIL. Lei 13.140, de 26 de junho de 2015. Dispõe sobre a mediação entre particulares como meio de solução de controvérsias e sobre a autocomposição de conflitos no âmbito da administração pública; altera a Lei no 9.469 , de 10 de julho de 1997, e o Decreto no 70.235, de 6 de março de 1972; e revoga o $§ 2^{\circ}$ do art. 6o da Lei no 9.469, de 10 de julho de 1997. Diário Oficial da União: Brasília, DF, 29 jun. 2015. Disponível em: http://www.planalto.gov.br/ccivil_03/_ato2015-2018/2015/lei/113105.htm. Acesso em 14 mai. 2018. Artigo 11.

${ }^{27}$ BRASIL. Lei 13.105, de 16 de março de 2015. Código de Processo Civil. Diário Oficial da União: Brasília, DF, 17 mar. 2015. Disponível em: http://www.planalto.gov.br/ccivil_03/_ato2015-2018/2015/lei/l13105.htm. Acesso em 14 mai. 2018. Parágrafo sexto do artigo 167.
} 
limitação da igualdade de acesso aos referidos cargos na Justiça do Trabalho, conforme foi estabelecido indevidamente pelo CSJT.

São esses tipos de conduta que demonstram uma centralização tão exacerbada ao ponto de ignorar aspectos sociais e logísticos por parte do CSJT, prejudicando pessoas que buscam acesso à justiça pelos métodos equivalentes para a solução de seus conflitos, quando apenas interesses próprios de uma classe são observados, incluídos de maneira sutil (e algumas vezes até mesmo explícita) no texto legal para beneficiar alguns que não terão expertise ou vocação para ocupar tais posições.

A demanda por conciliadores e mediadores nos Tribunais Regionais do Trabalho, afinal, acabará por não ter muitas opções de escolha com tais amarras feitas pela Resolução do CSJT, pela desigualdade com a qual trata as pessoas que poderiam ou não concorrer para tais cargos ${ }^{28}$ (certamente favorecendo alguns poucos, que se beneficiariam com tal medida quando os cargos de conciliadores e mediadores passassem a ser remunerados) e os demais aspectos que atravessam a questão da centralização.

\section{A INEFICÁCIA DA RESOLUÇÃO $\mathrm{N}^{\circ} 174$ DO CSJT EM FACE DAS}

\section{ESTATÍSTICAS}

Considerando-se todas as críticas feitas até o momento, podemos utilizar os elementos estatísticos fornecidos pelo CNJ, contidos em seus relatórios Justiça em Números, para averiguar se a Resolução do CSJT aqui criticada possuiu algum efeito durante o seu primeiro ano de vigência.

Nenhum outro ramo de análise poderia ser melhor para tal propósito do que a comparação entre os Índices de Conciliações dos anos de 2016 e 2017. Afinal, o suposto

\footnotetext{
${ }^{28} \mathrm{O}$ autor faz uma análise crítica de como os reais detentores do poder, defensores do Liberalismo, acabam por incutir seus ideais e conceitos em diversos aspectos das nossas vidas, principalmente pelas vias da Política e do Direito, buscando alcançar seus reais interesses sempre através de uma cortina supostamente "democrática" e "constitucional" (BERCOVICI, Gilberto. Soberania e Constituição: Para Uma Crítica do Constitucionalismo. São Paulo, QuartierLatin do Brasil, 2008, p. 157-214).
} 
objetivo de tal resolução seria aumentar tais números dentro da Justiça do Trabalho, tornandoa eficaz e preparada para exercer essa função.

Não foi percebida tal mudança, contudo. Enquanto em 2016, tal índice foi de 25,8\%, para o ano de 2017, tivemos uma diminuição para 24,8\%.

Gráfico 3 - Índice de Conciliação por Tribunal Regional do Trabalho em 2016

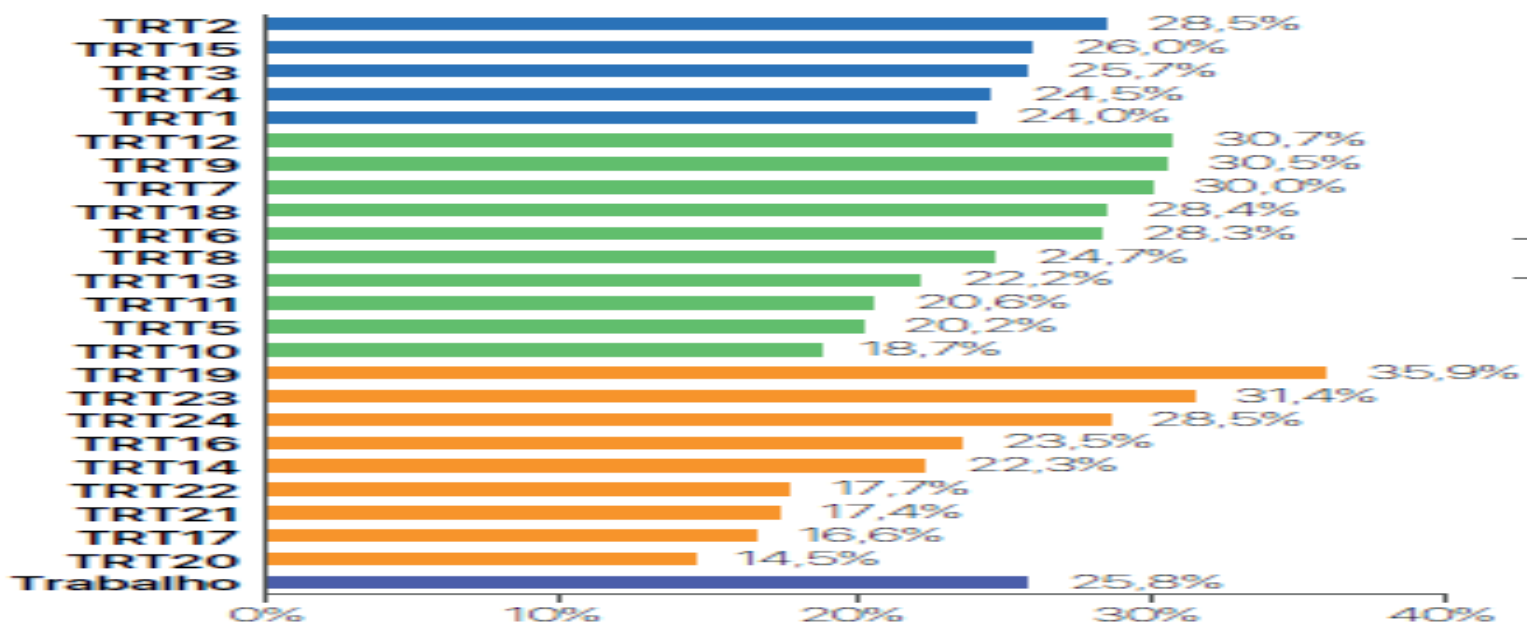

Fonte: BRASIL. Justiça em Números 2017: ano-base 2016. Conselho Nacional de Justiça Brasília: CNJ, 2017. p. 127.

Gráfico 4 - Índice de Conciliação por Tribunal Regional do Trabalho em 2017

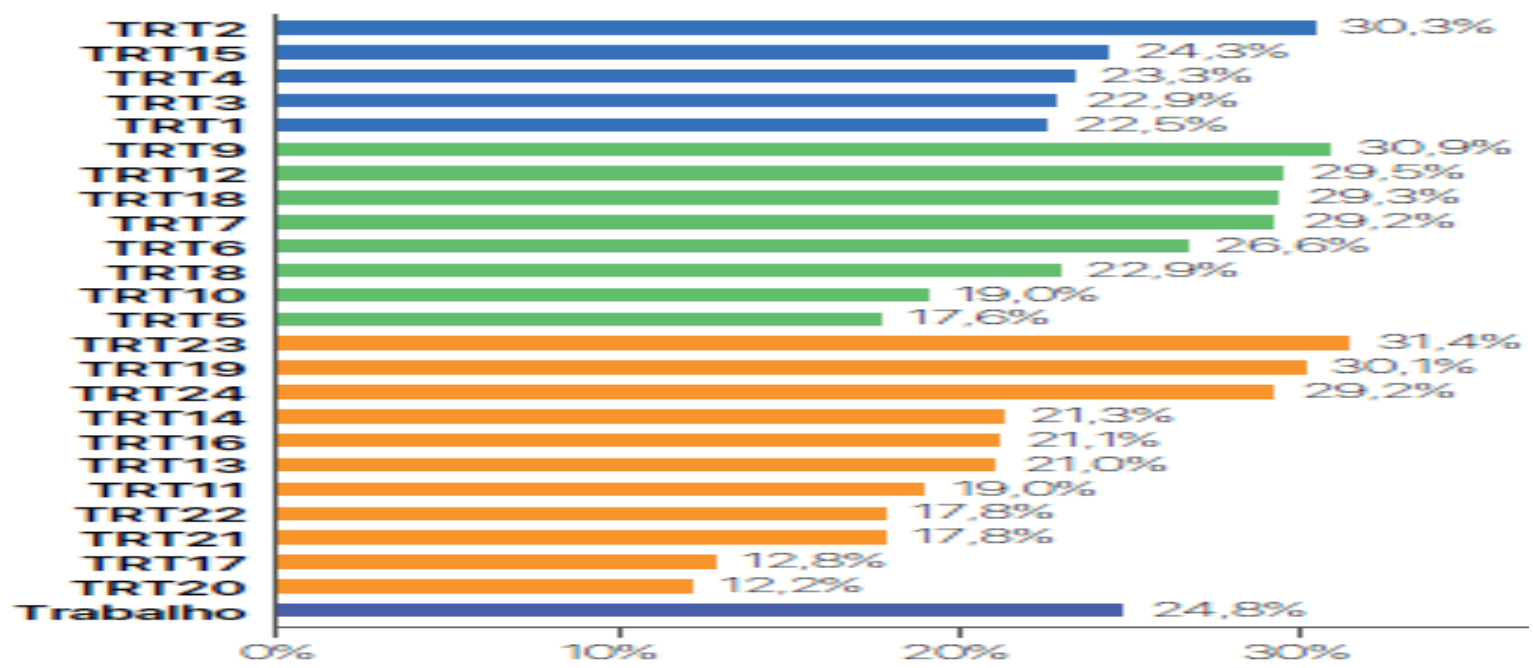

Fonte: BRASIL. Justiça em Números 2018: ano-base 2017. Conselho Nacional de Justiça Brasília: CNJ, 2018. p. 139. 
Na realidade, portanto, a capacidade de conciliação da Justiça do Trabalho diminuiu levemente.

Evidentemente, aqui não se pode afirmar que tal redução ocorreu por decorrência da Resolução do CSJT em análise, mas que tal regulação não foi capaz de auxiliar, no mínimo, para manter os patamares do ano anterior, isso é notório.

\section{CONSIDERAÇÕES FINAIS}

Quando analisamos a legitimidade do Poder, Ana Lucia Sabadell informa que tal condição "pode ser definida como um amplo consenso, no seio da sociedade, de que uma autoridade adquire e exerce o poder de modo adequado" ${ }^{29}$. Por meio desse trecho, percebemos que podemos adaptar isso para contextos que vão além das relações do Poder Executivo, para os quais a autora se referia originariamente.

Com base no que foi desenvolvido neste artigo, parece que esquecem ou ignoram estes magistrados seus objetivos institucionais, quando em posições de exercício de funções regulamentadoras - ao utilizar seus poderes de modo inadequado, tanto em face de políticas públicas (como já desenvolvido em outro ensaio), bem como ao agir contra princípios basilares, como o acesso à justiça e a igualdade em suas determinações - que desfavorecem a boa prática (regulamentada pelo $\mathrm{CNJ}$ ) dos meios equivalentes de gestão de conflitos, conforme aqui foi ilustrado.

Em verdade, a Resolução $n^{\circ} 174$ do CSJT evita que o caminho de descentralização da função jurisdicional dos juízes togados em direção aos cidadãos se concretize, promovendo assim que tanto seja inviável uma real distribuição do Poder decisório, como também que o processo possa se tornar algo mais democrático, conforme Gutiérrez e Cunha ${ }^{30}$ defendem como

\footnotetext{
${ }^{29}$ SABADELL, Ana Lucia. Manual de Sociologia Jurídica. 3 ed. São Paulo: Revista dos Tribunais, 2005 , p. 113. ${ }^{30}$ GUTIÉRREZ, Daniel Mota; CUNHA, Jânio Pereira da. Jurisidição Processual e Democracia: Advento da Audiência de Conciliação e de Mediação, efetivação dos meios equivalentes de acesso à justiça. Revista Opinião Jurídica, Fortaleza, ano 13, n. 17, jan./dez. 2015. Disponível em:
} 
condição essencial para a concretização dos princípios constitucionais, aqui apontados como violados em face das determinações do CSJT ao exercer o poder regulador dentro da sua esfera.

A busca pela legitimidade é uma tarefa que precisa ser cumprida diariamente pelos três Poderes de uma democracia e, quando algum desses se utiliza do direito para desrespeitar normas constitucionais em sua atuação, ainda mais em situações claramente benéficas para determinados grupos, isso corrói a legitimidade e a posição de garantidor de uma ordem que o Judiciário, supostamente, deveria defender.

Atitudes nesse sentido, por parte do Judiciário, acabam por influenciar a percepção dos brasileiros sobre o referido Poder. Não é por acaso que a confiança dos nacionais apresentou uma queda de 10 pontos percentuais entre 2013 a 2017, passando de $34 \%$ para $24 \%$, conforme a Fundação Getúlio Vargas ${ }^{31}$ constatou em relatório no primeiro semestre de 2017.

Enquanto os Poderes Públicos e o Direito forem utilizados para a manutenção do status quo centralizador e, dentro do Judiciário, para retenção da função jurisdicional, nada poderemos esperar de mudanças na efetivação da igualdade ou acesso à justiça previstos na Constituição Federal para todos.

\section{REFERÊNCIAS}

BERCOVICI, Gilberto. Soberania e Constituição: Para Uma Crítica do Constitucionalismo. São Paulo, QuartierLatin do Brasil, 2008.

BRASIL. Constituição (1988). Constituição da República Federativa do Brasil: promulgada em 5 de outubro de 1988, atualizada até a Emenda Constitucional no 99, de 14 de dezembro de 2017. http://www.planalto.gov.br/ccivil_03/constituicao/constituicaocompilado.htm. Acesso em 10 mai. 2018.

http://periodicos.unichristus.edu.br/index.php/opiniaojuridica/article/view/495/193. Acesso em 12 nov. 2018, p.108-131.

${ }^{31}$ RAMOS, Luciana de Oliveira; CUNHA, Luciana Gross; OLIVEIRA, Fabiana Luci de; SAMPAIO, Joelson Oliveira; BUENO, Rodrigo de Losso da Silveira; ÚBIDA, Giovanna. Relatório ICJBrasil - $1^{\circ}$ semestre/2017. São Paulo: FGV Direito SP - Escola de Direito de São Paulo, 2017. Disponível em: http://bibliotecadigital.fgv.br/dspace/bitstream/handle/10438/19034/Relatorio-

ICJBrasil_1_sem_2017.pdf?sequence=1\&isAllowed=y. Acesso em: 12 nov. 2018, p. 13-14. 
BRASIL. Justiça em Números 2017: ano-base 2016. Conselho Nacional de Justiça - Brasília: CNJ, 2017.

BRASIL. Justiça em Números 2018: ano-base 2017. Conselho Nacional de Justiça - Brasília: CNJ, 2018.

BRASIL. Lei 13.105, de 16 de março de 2015. Código de Processo Civil. Diário Oficial da União: Brasília, DF, 17 mar. 2015. Disponível em: http://www.planalto.gov.br/ccivil_03/_ato2015-2018/2015/lei/l13105.htm. Acesso em 14 mai. 2018.

BRASIL. Lei 13.140, de 26 de junho de 2015. Dispõe sobre a mediação entre particulares como meio de solução de controvérsias e sobre a autocomposição de conflitos no âmbito da administração pública; altera a Lei no 9.469, de 10 de julho de 1997, e o Decreto no $\mathbf{7 0 . 2 3 5}$, de 6 de março de 1972; e revoga o $§ 2^{\circ}$ do art. 6o da Lei no 9.469, de 10 de julho de 1997. Diário Oficial da União: Brasília, DF, 29 jun. 2015. Disponível em: http://www.planalto.gov.br/ccivil_03/_ato2015-2018/2015/lei/113105.htm. Acesso em 14 mai. 2018.

BRASIL. Tribunal Superior do Trabalho. Súmula $\mathrm{n}^{\circ}$ 425. O jus postulandi das partes, estabelecido no art. 791 da CLT, limita-se às Varas do Trabalho e aos Tribunais Regionais do Trabalho, não alcançando a ação rescisória, a ação cautelar, o mandado de segurança e os recursos de competência do Tribunal Superior do Trabalho. Diário Eletrônico da Justiça do Trabalho: Brasília, DF, divulgado em 30.04.2010 e 03 e 04.05.2010. Disponível em: http://www3.tst.jus.br/jurisprudencia/Sumulas_com_indice/Sumulas_Ind_401_450.html\#SU M-425. Acesso em: 31 jan. 2019.

CAPPELlETTI, Mauro; GARTH Bryant. Acesso à justiça. Porto Alegre, Sérgio Antonio Fabris, 1988.

CONSELHO NACIONAL DE JUSTIÇA. Resolução $n^{\circ}$ 125, de 29 de novembro de 2010. Dispõe Sobre A Política Judiciária Nacional de Tratamento Adequado dos Conflitos de Interesses no âmbito do Poder Judiciário e Dá Outras Providências. Diário Oficial da União: Brasília, DF, $1^{\circ}$ dez. 2010.2 Disponível em: http://cnj.jus.br/images/atos_normativos/resolucao/resolucao_125_29112010_110320161508 08.pdf. Acesso em: 9 mai. 2018.

CONSELHO NACIONAL DE JUSTIÇA. Programas e Ações - Conciliação e Mediação. Brasília, [s.d.], sítio eletrônico. Disponível em: http://www.cnj.jus.br/programas-eacoes/conciliacao-e-mediacao-portal-da-conciliacao. Acesso em: 14 mai. 2018.

CONSELHO SUPERIOR DA JUSTIÇA DO TRABALHO. Resolução $\mathrm{n}^{\circ} 174$, de 30 de setembro de 2016. Dispõe Sobre A Política Judiciária Nacional de Tratamento Adequado das Disputas de Interesses no âmbito do Poder Judiciário Trabalhista e Dá Outras Providências. Diário Eletrônico da Justiça do Trabalho: Brasília, DF, n. 2079, 5 out. 2016. Caderno Administrativo [do] Conselho Superior da Justiça do Trabalho, p. 1-6. Disponível em: http://www.csjt.jus.br/c/document_library/get_file?uuid=235e3400-9476-47a0-8bbbbccacf94fab4\&groupId=955023. Acesso em: 10 mai. 2018. 
FILPO, Klever Paulo Leal. Conflitos não-mediáveis ou conflitos latentes? Aportes interdisciplinares para pensar a mediação em juízo na Lei13.105/2015. Revista Juris Poiesis ano 19, $\mathrm{n}^{\circ}$ 19, p. 26-40, jan-mai. 2016. Disponível em: http://revistaadmmade.estacio.br/index.php/jurispoiesis/article/viewFile/2024/1035. Acesso em: 31 jan. 2019.

GUTIÉRREZ, Daniel Mota; CUNHA, Jânio Pereira da. Jurisidição Processual e Democracia: Advento da Audiência de Conciliação e de Mediação, efetivação dos meios equivalentes de acesso à justiça. Revista Opinião Jurídica, Fortaleza, ano 13, n. 17, p.108-131, jan./dez. 2015. Disponível

http://periodicos.unichristus.edu.br/index.php/opiniaojuridica/article/view/495/193. Acesso em 12 nov. 2018.

MAGALHÃES, Victor Alves e MELO, Marcelo Sampaio de Couto. Prejuízos de uma política pública sem gestão e estatísticas: o caso da Resolução No 174/2016 do Conselho Superior da Justiça do Trabalho. Revista Inclusiones, v. 5. n. 4, p. 95-107, out./dez. 2018. Disponível em: http://www.revistainclusiones.com/gallery/6\%20vol\%205\%20num\%204\%202018cruzvadillo octubrediciembrerv\%20inclu.pdf. Acesso em: 12 nov. 2018.

ORDEM DOS ADVOGADOS DO BRASIL - CEARÁ. Diga Não ao Laçador: campanha combate prática ilegal da advocacia. Fortaleza, $1^{\circ}$ out. 2014, sítio eletrônico. Disponível em: http://oabce.org.br/2014/10/diga-nao-ao-lacador-campanha-combate-pratica-ilegal-daadvocacia/. Acesso em: 14 mai. 2018.

RAMOS, Luciana de Oliveira; CUNHA, Luciana Gross; OLIVEIRA, Fabiana Luci de; SAMPAIO, Joelson Oliveira; BUENO, Rodrigo de Losso da Silveira; ÚBIDA, Giovanna. Relatório ICJBrasil - $1^{o}$ semestre/2017. São Paulo: FGV Direito SP - Escola de Direito de São Paulo, $2017 . \quad$ Disponível em: http://bibliotecadigital.fgv.br/dspace/bitstream/handle/10438/19034/Relatorio-

ICJBrasil_1_sem_2017.pdf?sequence=1\&isAllowed=y. Acesso em: 12 nov. 2018.

SABADELL, Ana Lucia. Manual de Sociologia Jurídica. 3 ed. São Paulo: Revista dos Tribunais, 2005.

WOLKMER, Antônio Carlos. Introdução aos Fundamentos de uma Teoria Geral dos "Novos" Direitos. Revista Jurídica - UNICURITIBA, Curitiba, v. 2, n. 31, p. 121-148, 2013. Disponível em: http://revista.unicuritiba.edu.br/index.php/RevJur/article/view/593. Acesso em: 9 mai. 2018.

Data de submissão: 25/02/2019

Data de Aceite: 10/12/2019 